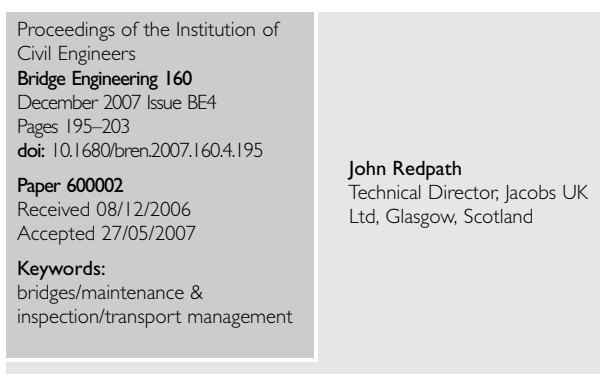

\title{
Pendel bearing replacement at A9 Kessock Bridge, Scotland
}

J. Redpath BSc, CEng, MICE

The A9 is the primary north-south trunk route in the Scottish Highlands and bypasses the city of Inverness by means of Kessock Bridge, a major cable-stayed structure spanning the Beauly Firth and opened to traffic in 1982. The bridge is a $1052 \mathrm{~m}$ long viaduct with a main cablestayed span of $240 \mathrm{~m}, 80 \mathrm{~m}$ back spans and a number of $64 \mathrm{~m}$ and $72 \mathrm{~m}$ approach spans. At the ends of the $80 \mathrm{~m}$ back spans, four pendel-type bearings were installed to accommodate uplift reaction due to loading on the main span. These pendel bearings became excessively worn over time and required replacement. This paper describes the design and construction issues associated with replacement of these critical structural elements, an operation made more challenging by the very constrained geometry and the need to maintain overall stability of the bridge under operational traffic conditions.

\section{INTRODUCTION}

The A9 forms the principal north-south highway route from the Central Lowlands of Scotland to the North West Highlands. To the immediate north of Inverness, Kessock Bridge crosses the Beauly Firth to the peninsula of the Black Isle and beyond (Fig. 1). The bridge is a $1052 \mathrm{~m}$ long viaduct with a main cable-stayed span of $240 \mathrm{~m}$ with approach spans as shown in Fig. 2.

\section{I.I. Superstructure}

The deck is a steel orthotropic type with two $3 \cdot 3 \mathrm{~m}$ deep plate girders on the deck edge bounding a series of regularly spaced transverse cross-girders supporting a $14 \mathrm{~mm}$ plate deck reinforced by longitudinal trough stiffeners (Fig. 3). At the ends of the $80 \mathrm{~m}$ back spans, four pendel-type bearings were installed to accommodate uplift reaction due to loading on the main span. The pylons reach a height of $42 \mathrm{~m}$ above deck level and are single-cell stiffened steel box columns. The pylons are integral with a transverse box that spans the main bearing positions at deck level providing a U-frame structure at these locations. Sixty-four spiral strand, pre-stretched cables of 83, 93 and $101 \mathrm{~mm}$ dia. are disposed symmetrically in harp arrangements about the four pylons, anchoring at deck level in twin-cell anchorage boxes cantilevered outboard of the main girders. Connections to the pylons are achieved through twin-diaphragm arrangements.

\section{I.2. Articulation}

The superstructure of the bridge is continuous between abutments. The main pier south of the navigation channel (pier 7) acts as the longitudinal anchor for the superstructure with all deck expansion taking place from this point. The expansion joints and bearings at both abutments allow for a total of $500 \mathrm{~mm}$ longitudinal expansion. All bearings other than those at pier 7 are rubber pot bearings that provide pinned connections with the required amount of sliding capacity for expansion and contraction.

The bridge spans the Great Glen Fault, which has a record of seismic activity. Provision was made in the original design to accommodate up to $0 \cdot 1 \mathrm{~g}$ horizontal ground acceleration by means of twin hydraulic seismic buffers that are incorporated into the north abutment, each with a shock loading capacity of 400 tonnes.

\section{I.3. Substructure and foundations}

The substructure consists of 12 piers and two abutments of reinforced concrete construction. The approach span piers comprise twin independent rectangular columns supporting the main girders of the superstructure. The main piers located directly below the superstructure pylons have a portal frame configuration providing the principal resistance to lateral wind loading. With the exception of pier 12, all columns are supported on isolated foundations. Pier 12 is supported on a tied base where a beam links the two footings at foundation level. Piers 6 to 10 are supported on steel piled foundations. All other piers are supported on conventional spread foundations. Further information can be obtained from several articles on Kessock Bridge published shortly after construction. ${ }^{1-6}$

The pendels (the word deriving from the German for pendulum) are vertically installed steel link bars articulated by steel pins top and bottom (Fig. 4). Four pendel assemblies connect the deck edge plate girders to the column tops at pier positions 6 and 9-that is two south and two north pendels in total. The pendels are designed to transmit both the tensile uplift reaction under main span live loading and, conversely, the compression reaction due to live loading on the $80 \mathrm{~m}$ and $72 \mathrm{~m}$ spans. The links are required to be sufficiently stocky to transmit compression loading but long enough to accommodate thermal displacements on the bridge without excessive relative longitudinal displacement between top and bottom pins. The pendels were designed to be load neutral under permanent loads and are thus 


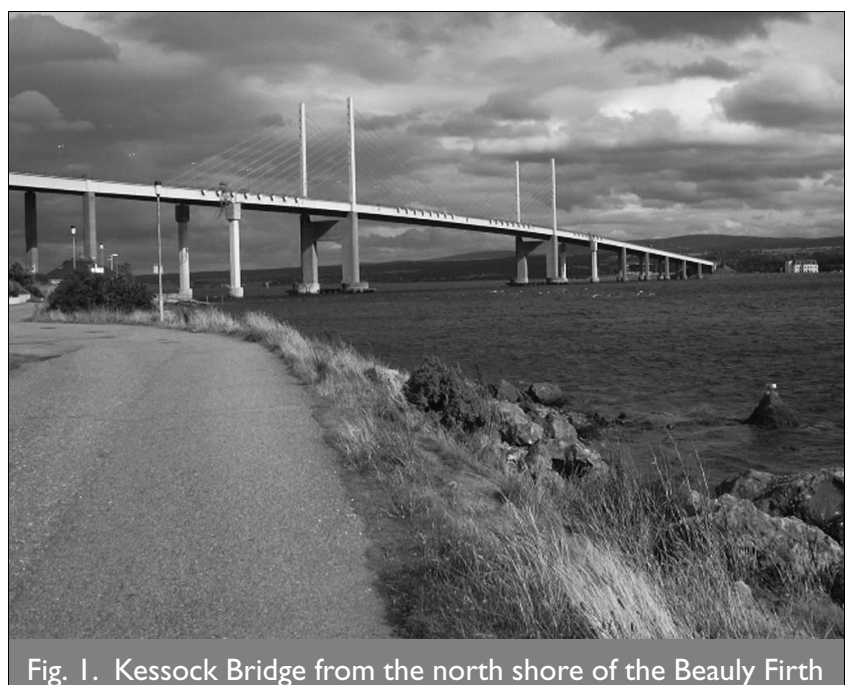

subject to reversed loading as frequently as traffic loading fluctuates on the deck-many times every day.

A routine load capacity assessment of Kessock Bridge in the late 1990s identified a requirement for strengthening of the webs on the two main edge girders, culminating in the completion of a separate web strengthening contract in 2003. However, partly as a result of the inspection for assessment for strengthening and in response to reports from the bridge maintenance crew,

cognisance was taken of considerable wear at the pendel bearing surfaces. Displacement monitoring between 1997 and 2001 had determined that the wear rate was significant and was manifest on the bridge by a fairly loud metallic 'clunking' noise as loads in the pendel assemblies reversed due to traffic movement overhead. The wear also resulted in a pronounced vertical play in the pendel assemblies.

The four pendel assemblies comprise pairs of vertical steel links connecting the pier column tops with the deck girders. Each link is $4 \cdot 8 \mathrm{~m}$ high, $0 \cdot 8 \mathrm{~m}$ wide, $0 \cdot 1 \mathrm{~m}$ thick and weighs $3.2 \mathrm{t}$. The pendel pins are cast steel of $375 \mathrm{~mm}$ dia.. The live load reactions in each pendel assembly vary from approximately $6000 \mathrm{kN}$ tension to $4000 \mathrm{kN}$ compression under normal operation.
Because the pendels are load neutral under dead load (under the relatively small loading of a single heavy goods vehicle crossing the bridge for example), the tension reaction in the pendels was sufficient to raise the assembly through the height of the cumulative wear of the bearing components-some $18 \mathrm{~mm}$ in one of the pendel assemblies. The assembly then fell that distance as load was reversed once a vehicle crossed the pendel pier. Consequently, the bearing surfaces very frequently impacted with considerable force accompanied by the loud 'clunk' audible from the footways on the deck. Monitoring of the wear in the bearings had shown that wear had accelerated since 1995 and it was conjectured that this was due to the ingress of particulates into the tolerance space between bearing surfaces during grit blasting for a bridge repainting contract in 1995. However, the bridge maintenance crew confirmed that a pendel 'clunk' had been a noticeable feature on at least one of the pendels since shortly after the bridge opened. This was confirmed by project correspondence within a year of opening. It was clear that with the passage of time all four pendels had become noisy.

An assessment of the wear rate indicated that in the medium term, there was no risk, that the apparent wear would consume the materials to the point at which load capacity would be affected. However, had the wear been allowed to progress, impacting of the bearings was bound to accelerate the process and the progressively increased noise would at some point have the potential to raise public concern-this alone would have presented a serviceability problem. A decision was taken to remedy the situation and, as a subset of the separate strengthening design, remedial options for the pendels were investigated.

\section{OPTIONS}

A considerable number of factors had to be accommodated in the development of options, but the following were particularly pronounced.

(a) The A9 being the key trunk road link from Inverness to the north, one of the primary factors affecting the development of remedial options was the need to maintain traffic operation at all times.

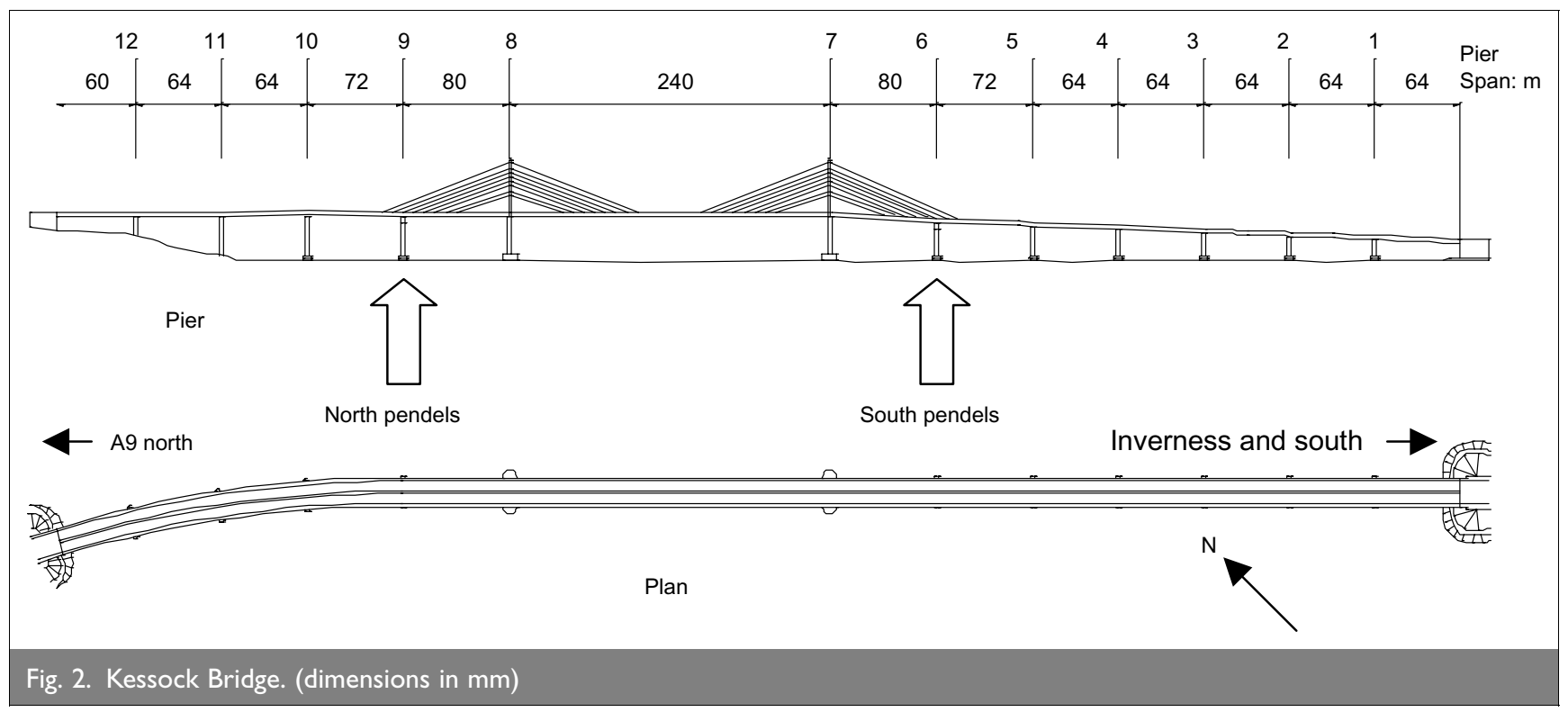




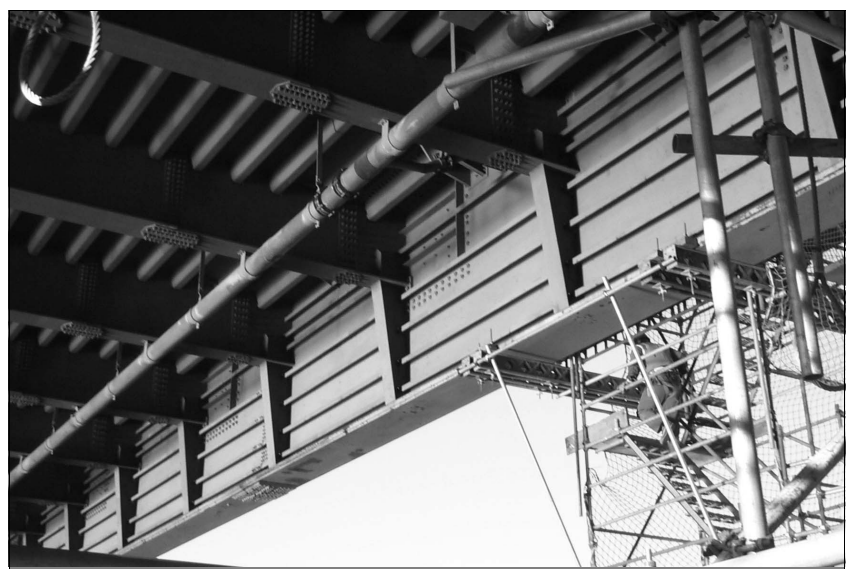

Fig. 3. Underside of deck

(b) The original pendel bearings were housed in hollow chambers contained within the tops of slender reinforced concrete columns. The removal and replacement operation was therefore greatly constrained by the geometry of the existing pendel chambers.

Clearly, removal and replacement of the bearings temporarily removes the reaction at the pendel piers. To maintain unrestricted traffic on the bridge during this period would have required a temporary tie-down arrangement that would have been capable of providing the full reactions. Preliminary design calculations and appraisals of various temporary link geometries indicated that the temporary works necessary to provide an alternative load path for the full design reactions would have been very difficult to install and maintain, would have physically impeded the removal and replacement operations and, as a result, would have been very costly.

A better balance was struck by deciding to limit traffic loading during the pendel 'outage' and to devise a removal and replacement operation that limited the outage to two weekend periods. Traffic flow on weekends is relatively light and lacks the peak flows present during weekdays. The client was therefore willing to accept restricted traffic flow on weekends but required unrestricted peak-hour weekday operation.

Kessock Bridge carries the A9 in dual carriageway with crossover points immediately to the north and south of the bridge. Thus, the provision of contra-flow traffic management was straightforward. However, the geometry of the existing pendels housed in very constrained chambers made it impossible to remove and replace the bearing components in the short periods required.

During the construction of the bridge, the pendels were originally installed and connected by placing the links in the pendel chambers prior to the deck girders being craned into position. The links lay against the chamber walls awaiting completion of the deck steel and were swung into position and connected as one of the last operations in the construction sequence. Once in place and connected, the links and bottom bracket assembly, a $5 \mathrm{t}$ welded steel assembly, could not be removed from the pendel chamber through the very limited aperture available which, in any case, was almost wholly blocked by the superstructure. In addition, the extremely limited working space in the chamber had made routine maintenance, such as lubrication of the bearing surfaces, difficult and uncomfortable for the maintenance crew throughout the years. Thus, in comparison with the replacement option, the far more demanding in situ refurbishment of the bearing surfaces in the chambers was deemed to be inherently hazardous and, due to the cramped space, practically unrealistic. Furthermore, in situ refurbishment would certainly have been a very protracted operation resulting in pendel outages far in excess of the time constraints available.

The solution adopted was therefore to replace the components of the pendels rather than refurbish the existing components in situ. The operation was thus essentially reduced to a swapping out and in of components, resulting in a very short pendel outage and thus a very short contra-flow period. The comparative cost of fabricating replacement pendel components was low given the other cost drivers.

While the limited traffic loading enabled a reduction in the reactions to be accommodated during the pendel outage, temporary links that could accommodate tension and compression loading and at the same time be physically installed in such a way that they would not themselves impede the pendel component swap were deemed to be impractical. A better approach was to employ kentledge loading on the deck to counter the reduced uplift loading during the pendel outage. The compressive reaction was supplied by a system of jacks between the substructure and deck. The internal dimensions of the existing chamber made it impossible to accomplish the component swap and were, in any case, incapable of supporting the necessary jack load.

A larger pendel chamber was conceived. This solved a number of problems.

(a) The chamber walls could be designed to accommodate the jacking forces necessary to unload the pendels under combined kentledge and contra-flow traffic. The kentledge provided was designed to overcome the maximum tensile reaction generated from the limited contra-flow traffic.

(b) The increased volume within the chambers and the larger top aperture would allow the removal and replacement of the pendel components in the 'special weekend' periods available.

(c) The larger chambers would greatly improve access to the pendels for future routine maintenance, allow the pendels to be unlinked in future and, without the removal of components, replaceable bearing bushes could be installed should further wear occur. Thus, future bush replacement could be accomplished in situ in two traffic-managed weekends under only kentledge and jacking.

The arrangement of enlarged pendel chamber and jacks is shown in Figs 5 and 6. The new pendels are shown in Fig. 7.

\section{DESIGN}

The replacement pendels were geometrically identical to the original pendels although some minor modifications were made to assist future maintenance. The principal difference was that for the new links, the lower bracket and the refurbished upper bracket incorporated replaceable steel bushes. As mentioned 


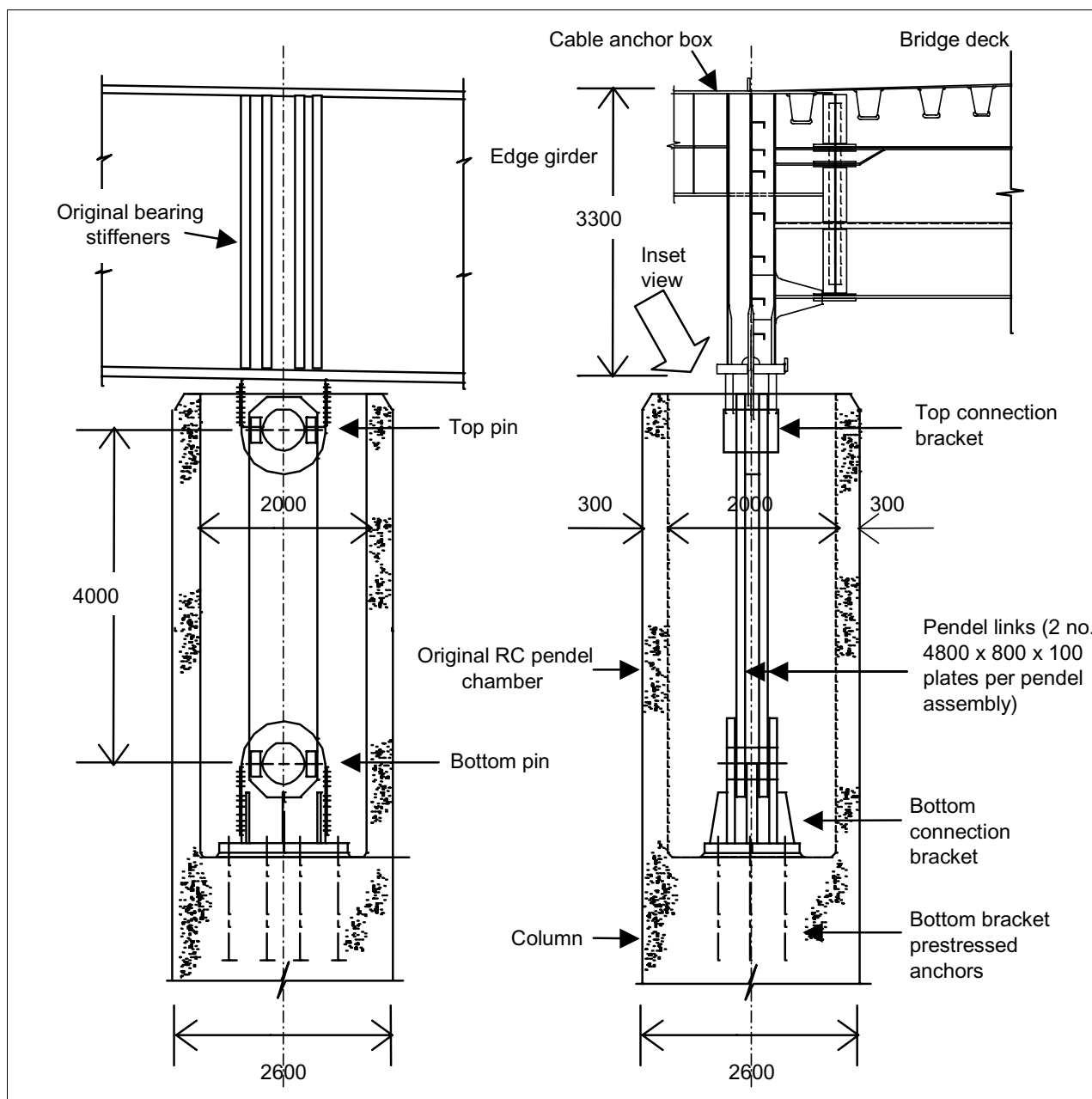

(a)

(b)

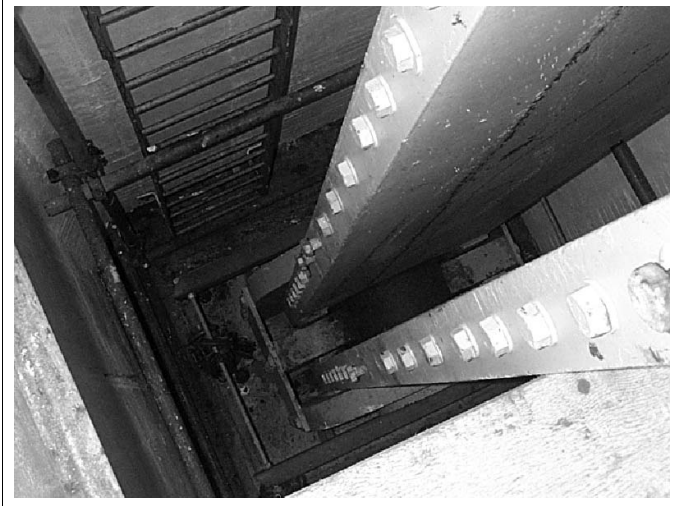

(c)

Bridge: $+0 \cdot 15$ to $0.35 \mathrm{~mm}$ on bearing surface diameter and -0.25 to $-0.40 \mathrm{~mm}$ on the diameter of the pin. The maximum allowable tolerance was thus $0.75 \mathrm{~mm}$-halving the tolerance allowed in the original. In addition, pin and bearing surface 'cylindricity', a measure of true circularity and pin straightness, was specified to be less than $0 \cdot 025 \mathrm{~mm}$. This fairly stringent requirement was in response to a phenomenon reported by bridge maintenance personnel who had in the past constructed an ad hoc locking bar across each of the original keeper plates at the pin ends to prevent the pins auto-rotating to align the vertical force line across the minimum diameter of the presumably slightly outof-true (i.e. ovalled) original pins. The maintenance crew had adopted a practice of manually rotating the pins by $90^{\circ}$ every six months and locking their position to distribute wear over the entire pin surface. By specifying the very low tolerance on cylindricity-that is, not only on diameter but also on pin length-it was intended that this phenomenon should be avoided without manual intervention.

A number of options for bush material were considered, including phosphor bronze and self-lubricating materials.

However, due to material geometric and bearing pressure limitations, the replaceable bush arrangement chosen comprised $14 \mathrm{~mm}$ thick grade S355J2G3 steel. The bushes were located in the closed

previously, there was evidence that wear in the pendel bearing surfaces had been aggravated by the ingress of grit following repainting. Future procedures for maintenance painting will recognise this and measures will be taken to prevent a recurrence. However, the ingress was partly assisted by the relatively generous tolerances between the pin and holes in the links. The replacement pins were $375 \mathrm{~mm}$ dia. grade BT1 low alloy cast steel to BS $3100 .^{7}$ In the UK there are very few applications of pendel bearings, although similar pendel devices were used on the Queen Elizabeth II Bridge at Dartford. Specification of the new tolerances was guided by the closer tolerances provided at QEII circular apertures to a 'light interference fit' with the half-circular bushes held by M10(4.6) countersunk set screws. All bushes are able to be lubricated by means of greasing holes through the bushes via channels within the pendel connection brackets and pins. These were initially charged with molybdenum disulphide grease with ongoing lubrication carried out at intervals.

The upper bracket connecting the pendel assembly and the bridge deck girder was by means of three lugs-a central web extension lug that projected through and below the lower flange of the edge 


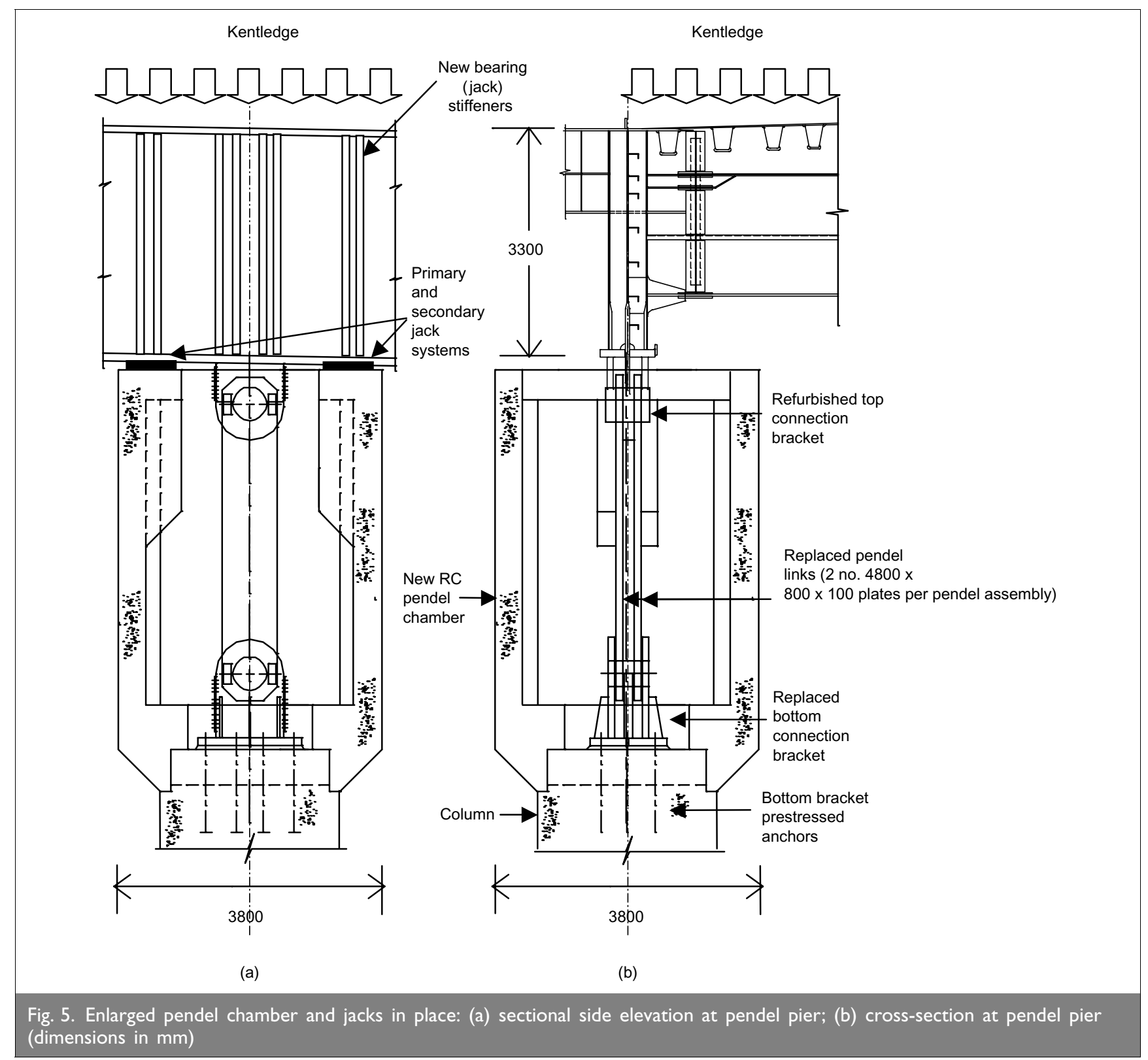

girders containing a fully circular pin aperture and two adjacent rectangular plates with semicircular bearing surfaces (Fig. 8).

The central bearing pin hole in the web extension was obscured by the pendel links and, consequently, the degree to which this hole had worn against the upper pin was unknown prior to

refurbishment. The central web extension lug was a $120 \mathrm{~mm}$ thick plate projecting down through a slot in the lower flange of the edge girder. The lug was butt welded to a locally thickened $60 \mathrm{~mm}$ girder web. Removal and replacement of this lug in the short pendel outage window was considered. However, it was judged that the cutting and refitting of the lug, involving on-site large fullpenetration butt welding at the very exposed location in the very short time available, presented a potential for considerable delay and technical difficulty not least with the alignment problems that may result from weld heat distortion. It was decided instead that, once exposed, the upper bracket hole in the web extension lug would be reamed in situ and bushes installed.

The pier columns supporting the pendels were discrete slender columns of $2.6 \mathrm{~m}$ square section with $500 \mathrm{~mm}$ rounded corners. The provision of an enlarged pendel chamber at each of the four affected columns presented an aesthetic challenge as this would clearly alter the appearance of the bridge. The chamber design chosen is the least possible enlarged section satisfying the pendel replacement operation and comprises an enclosed $3.8 \mathrm{~m}$ square section with $500 \mathrm{~mm}$ rounding of the corners and splays reducing

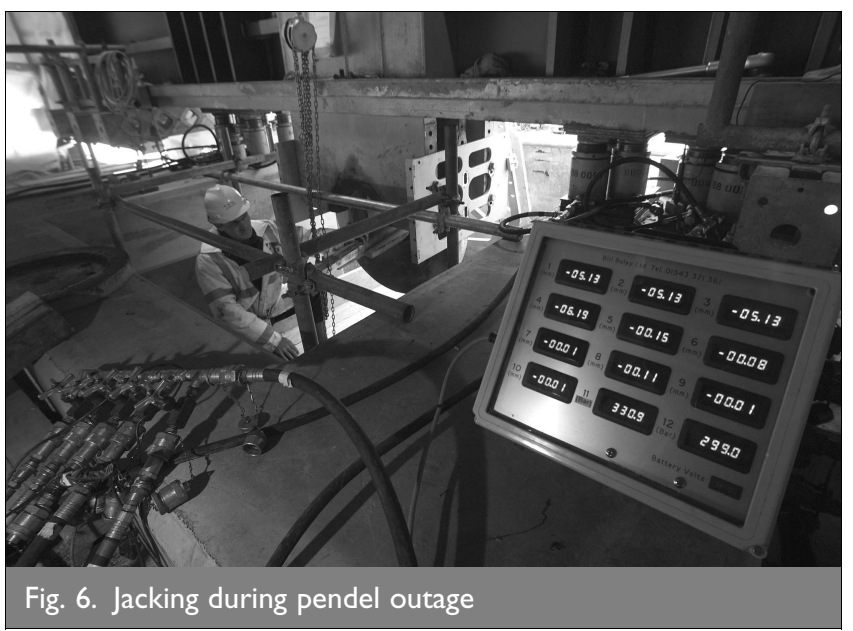




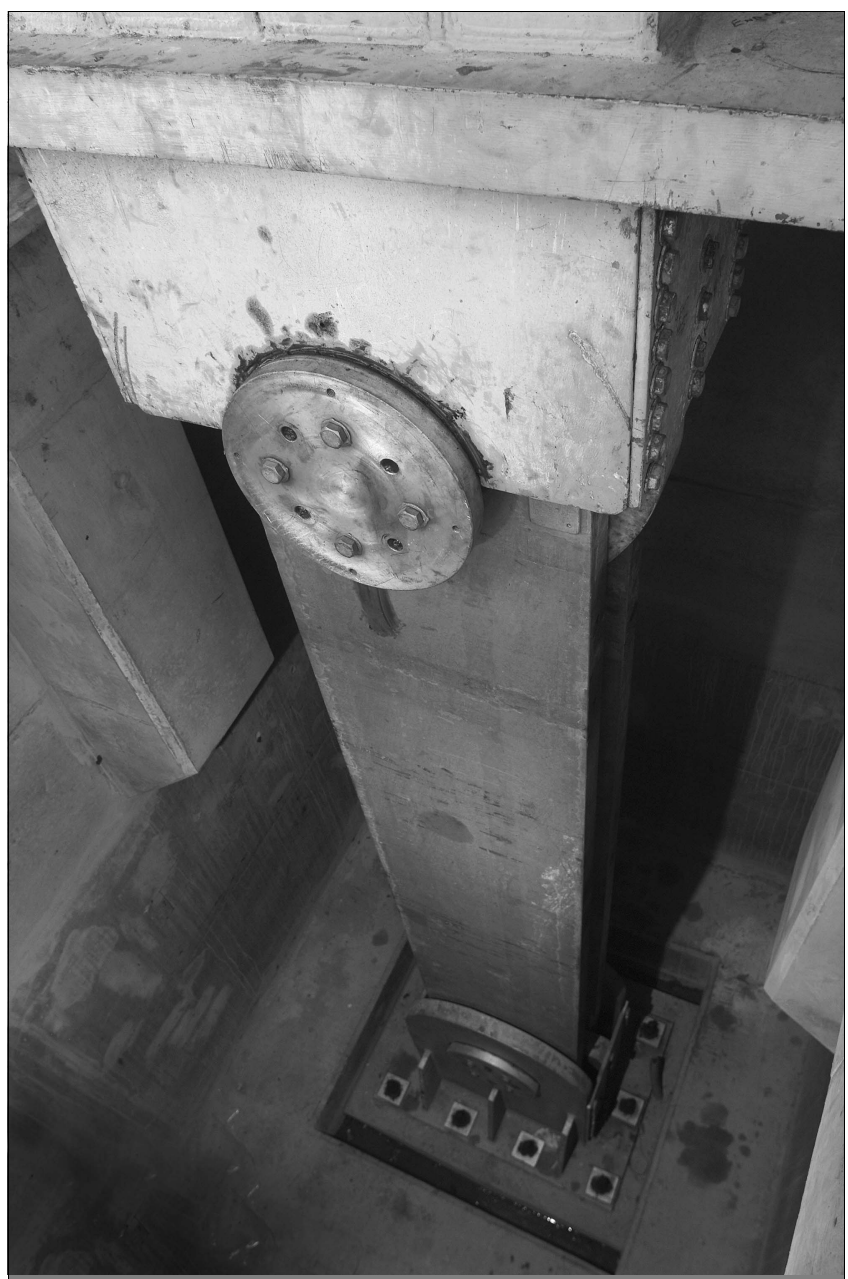

Fig. 7. New pendels in place

the dimension to the original section at the chamber base. The enlarged chambers have a 'crows nest' appearance.

The design was subject to aesthetic review and it was judged that while it could not be said that the new chambers actually improved the appearance of the bridge, neither did they detract significantly from the appearance. On balance, it was judged that

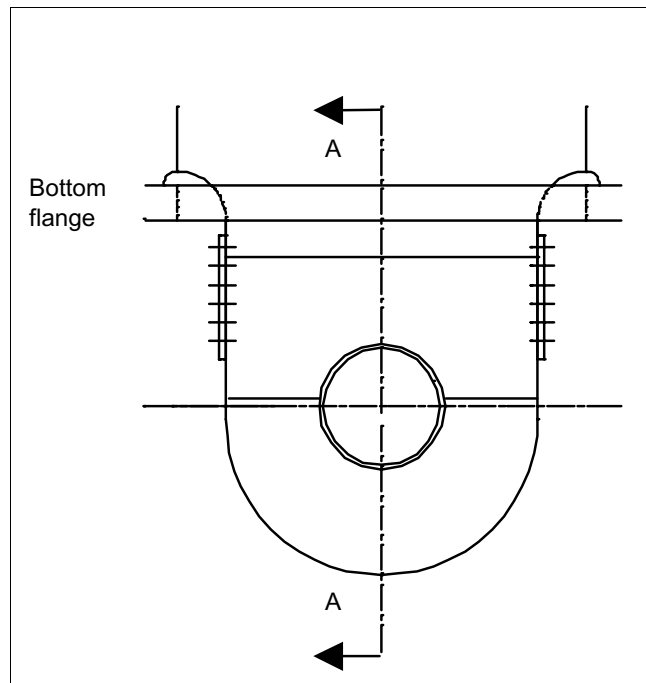

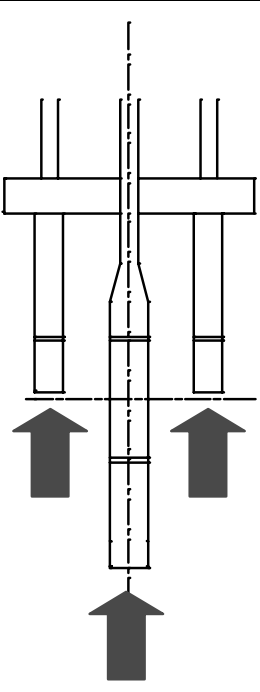

A-A

Compressive reaction
Fig. 8. Upper connecting bracket

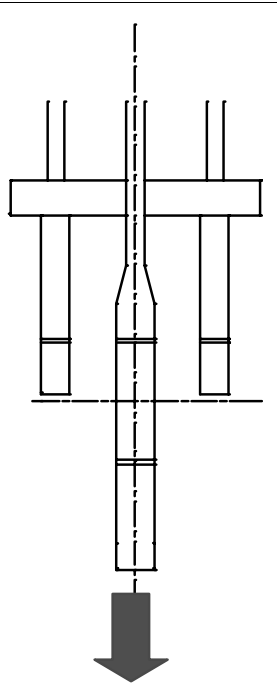

A-A Tensile reaction the overall effect on the bridge's appearance was neutral and therefore acceptable given the engineering imperatives. Solid CAD modelling was employed to demonstrate the altered appearance of the column heads as shown in Fig. 9. The model also shows the new web stiffeners designed to accommodate temporary loads from the jacks fore and aft of the pendel link.

The walls of the enlarged chamber comprise $400 \mathrm{~mm}$ thick heavily reinforced concrete. The chambers are only ever loaded during jacking and this load is transmitted in plane on the north and south walls, which are internally reinforced by internal reinforced concrete T-brackets cast monolithically with the walls. Jack support positions were designed to accommodate two independent jack systems, a primary and a backup. The jacking procedure required that the backup jacks followed the primary system to ensure that the backup system was immediately available with minimal displacement if pressure was lost in the primary system. A failure of the backup system was catered for by allowing a $3 \mathrm{~mm}$ displacement onto locking rings on the jacks with traffic stoppage until the jack system was rectified. In practice, none of the backup procedures were required.

The north and south jacks were hydraulically linked to allow deck rotation about a point equidistant between to ensure that the resultant reaction was concentric with the columns-that is, the jacks were able to inflate and deflate under maintained pressure. The slender columns deflect significantly under lateral loading and their slenderness was an important factor originally in determining the length of the pendel links (the length ensures that under maximum longitudinal thermal displacement combined with maximum compression reaction, there is little lateral component of load at the column top due to the link's inclination).

To contain the jacks on the wall tops within the width of the girder bottom flanges, the primary jack seating area was made concentric with the wall centre. However, the backup system was inboard of the wall centre and, if activated, would have generated considerable flexural effects in the north and south walls. The consequence of the compact chamber size and the large forces transmitted under jacking is that the north and south walls need to be very heavily reinforced. The connection at the base of the chamber onto the column top was also very heavily reinforced to prevent shear failure; the base ring beam prevents the chamber from 'telescoping' down the column under maximum jack loadings. Reinforcement detailing required precise three-dimensional design, visualisation, scheduling and bending, and made extensive use of couplers (Fig. 10).

The combined in-plane and bending load effects in the chamber were analysed by means of 3D finite-element 


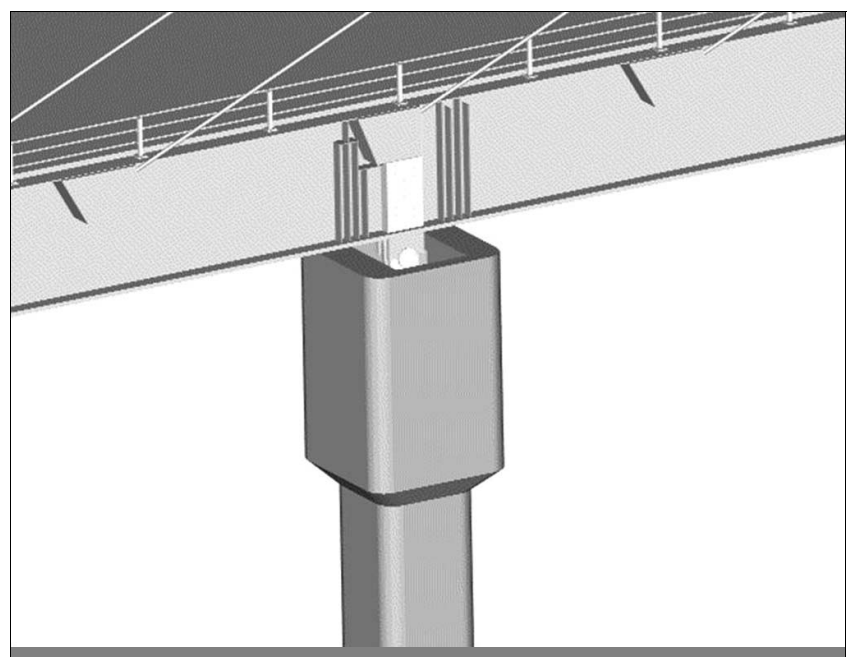

Fig. 9. Rendered solid model of the new pendel chamber

shell modelling with reinforcement requirements calculated using contouring of Clark-Nielsen results fields. ${ }^{8,9}$ Because of the very stocky aspect of the chamber walls, the shell model was further verified by comparing displacements and stresses with a 3D finite-element solid model (Fig. 11).

\section{CONTRACT AND TRAFFIC MANAGEMENT}

The design was completed in late 2001 and tendered on the basis of a traditional remeasured contract form to the ICE 5th Edition Conditions of Contract. ${ }^{10}$ The contract was awarded in December 2002 with commencement on site in January 2003 and substantial completion in June 2003. The final cost of the works was $£ 1 \cdot 2$ million.

The contract allowed ad hoc single lane closures during all periods except during the two-hour-long morning and evening weekday peaks; traffic management during the contract was satisfactorily uneventful. The focus of the construction effort was to enable the pendel links to be removed and replaced within two weekends; these were arranged to take place in June 2003. The planning of the 'special weekends' required great care and considerable contingency planning was carried out to ensure that all possible outcomes were catered for.

Programming at the design stage had indicated that while it was possible to complete the removal and replacement of the two pendels on the east side in one weekend with the two on the west following on another weekend, physical uncertainties suggested that a continuous four-day period should be allowed in the contract. Therefore two 'special weekends' were defined in the contract as two 'Friday through Monday' periods. As the inclusion of two weekdays in the contra-flow weekends meant that peak-hour delays were possible, a lane rental component was introduced into the contract to encourage expeditious replacement operations. A bonus/charge arrangement was specified for the deployment of contra-flow traffic management in the peak hours on the Friday and Monday. In practice, through a combination of very careful planning by the contractor, fortuitous weather conditions and lack of any of the significant adverse contingencies occurring, bonuses were paid on both special weekends.

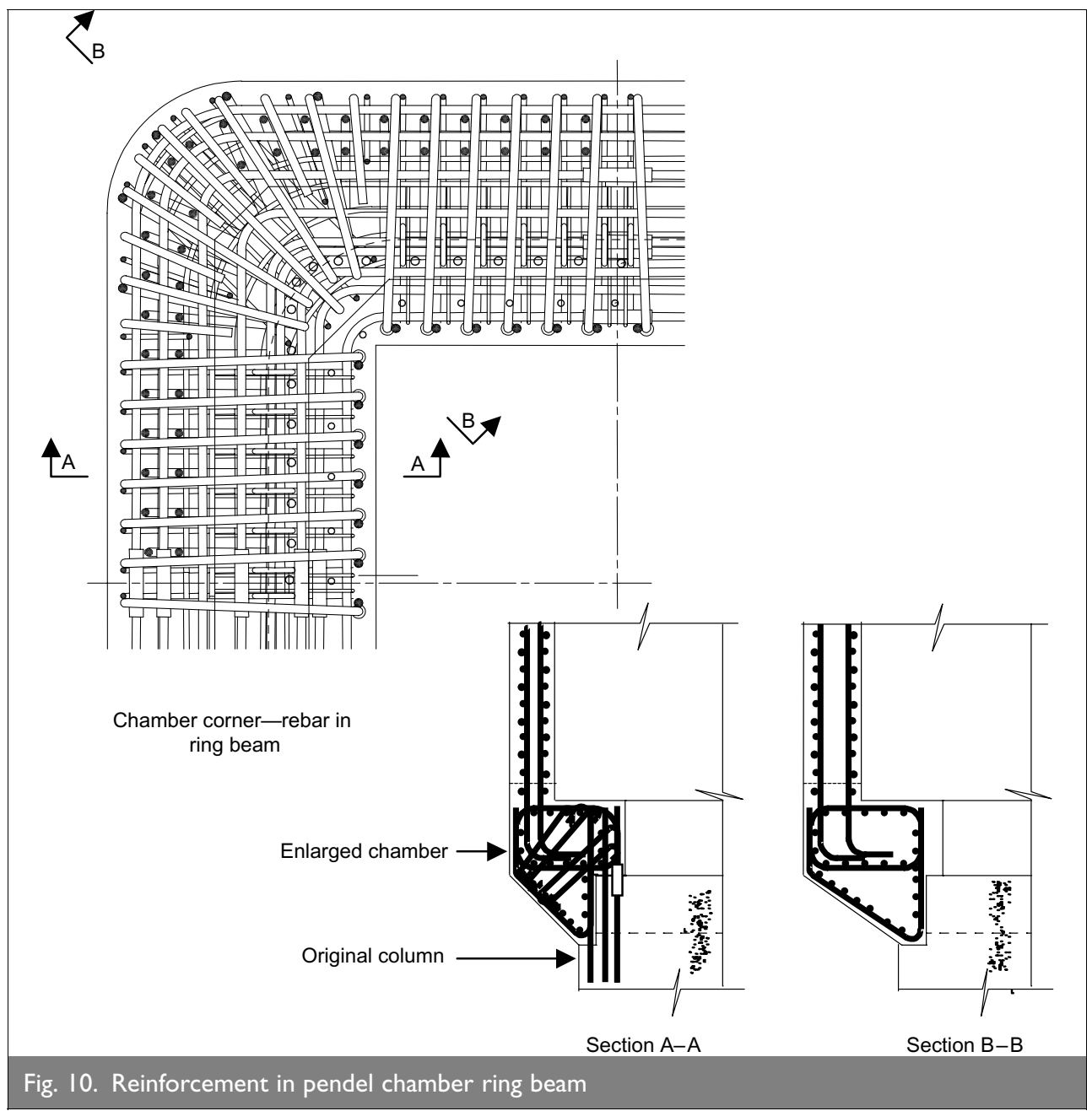

\section{CONSTRUCTION}

The contractor opted to construct scaffolding cages around the heads of the pendel piers to enclose the column heads and provide crossconnecting walkways. The free access afforded by this arrangement proved to be a significant factor in the rapid progress of the works.

The existing pendel chambers were demolished by vertical saw cutting and lifting away of segments of the walls to expose the pendel links and lower bracket assembly (Fig. 12). The walls were constructed in three lifts, the most complex of which was the ring beam connection to the heads of the columns. As the reinforcement for the ring beam was both dense and complex, it was agreed that a trial erection of the reinforcement at the subcontractor's yard would be a worthwhile exercise (Fig. 13). This proved to be the case and allowed the development of a 


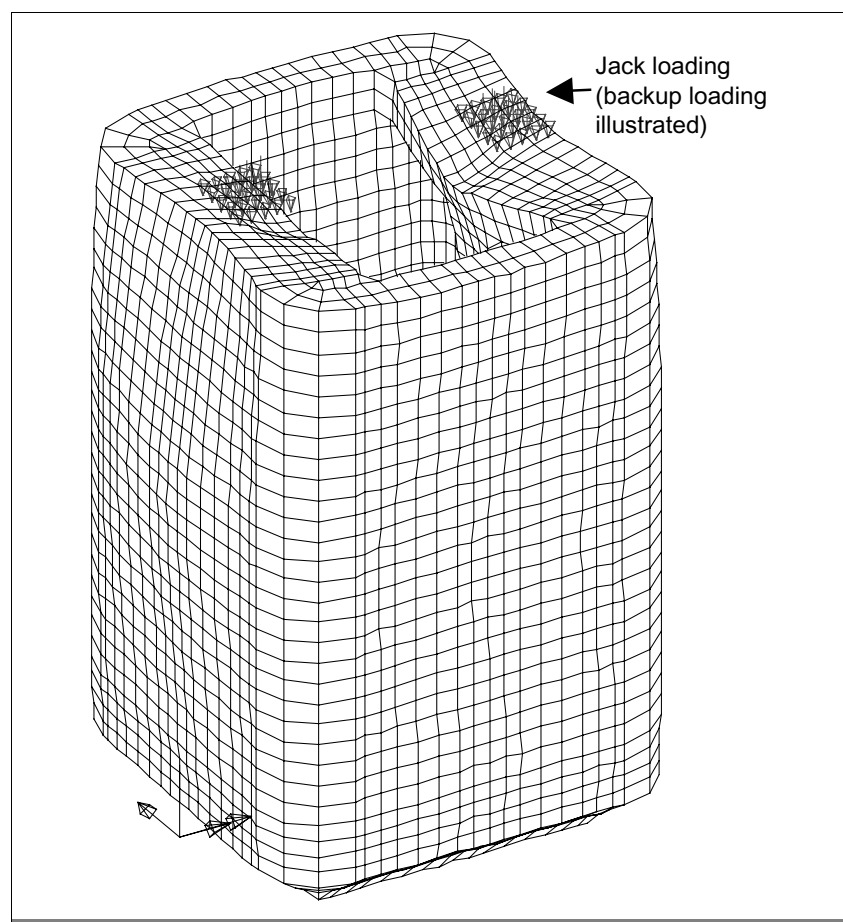

Fig. II. Deformed (exaggerated) mesh of chamber solid model under backup jack loading

semi-prefabricated approach that was successfully implemented at the column tops.

As the final lift formwork was being prepared on one of the pendel chambers, it became clear that during the slip forming of the original construction, the columns had twisted slightly resulting in the column's section not being exactly square to the deck girders. A slight outward column deflection also reduced the available aperture for the removal and replacement of the pendel lower bracket to within only a few millimetres of the bracket's base plate dimension. This was solved by shifting the position of the jack bearing brackets in the walls slightly off-centre to align with the girders (Fig. 14). While careful measurement of the base plate indicated that there was still just sufficient space available to remove and replace the $5 \mathrm{t}$ lower bracket, as an additional precaution the inside cover concrete on the outer wall was omitted from the pour, providing an additional $45 \mathrm{~mm}$. In the

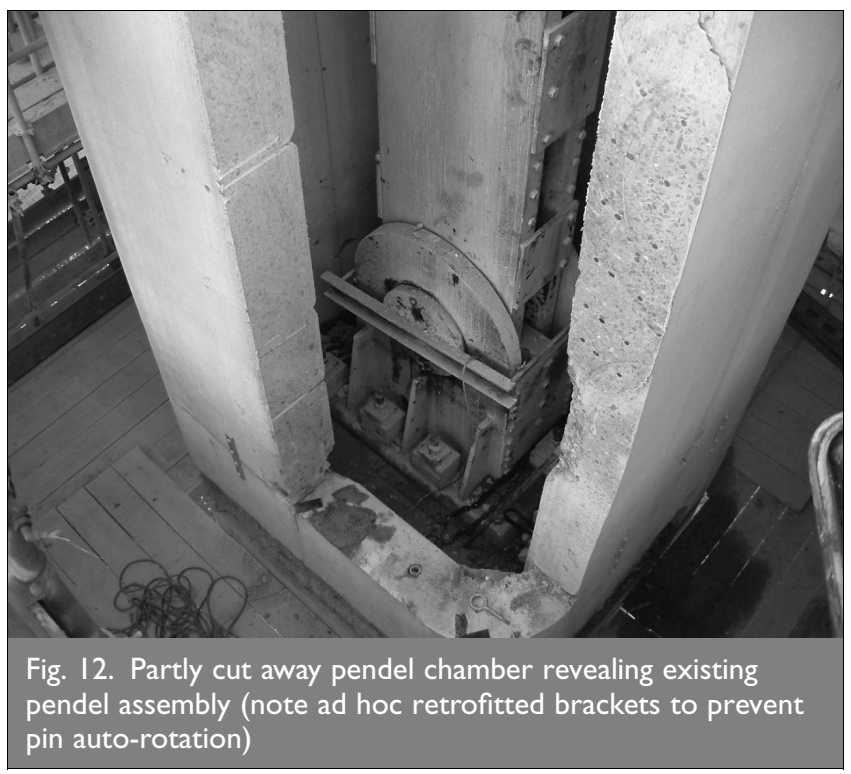

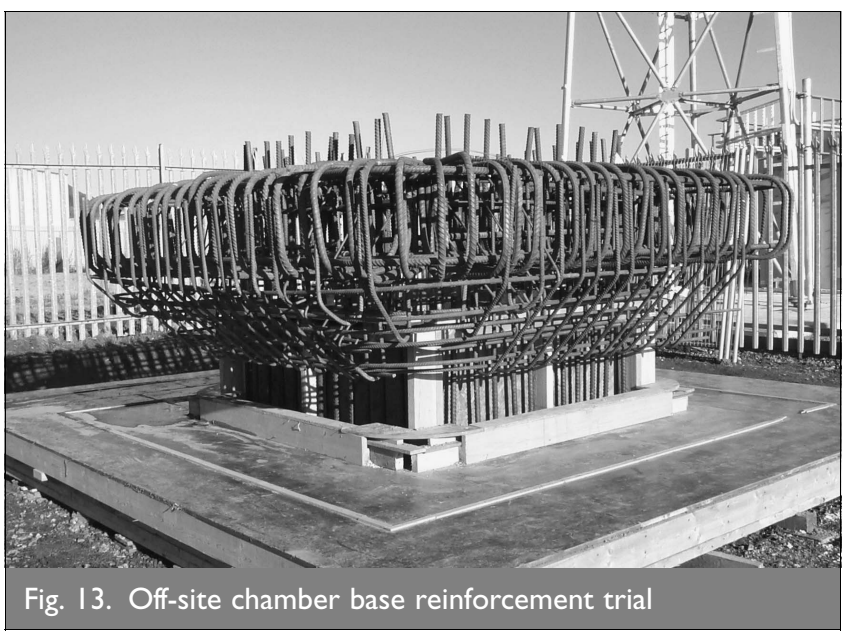

event, the bracket was removed and replaced without incident. Had the cover concrete been in place it almost certainly would have been damaged in any case by manhandling of the bracket and would have required repair.

Kentledge was provided by a number of flatbed trailers loaded with concrete blocks. The contract documents had prescribed areas in which these loads could be parked. The kentledge included the weight of the cranes positioned at each of the two pendel positions in each special weekend (Fig. 15 shows the NW pendel replacement operation with the SW out of view).

Jacking was carried out without incident. After inflation by hand pump, the jacks on the north and south pendel piers were monitored digitally from one location (Fig. 6). As jack inflation and load transfer off the pendels took place overnight on the Friday, traffic loading was negligible. Such was the mass of the kentledge along with very calm weather conditions, there was no flutter in pressures in the jacks. The pressure indicated that the transferred jack loads were within a very small tolerance, equal to the reactions calculated in the analysis model for the bridge. This provided a useful confirmation of the correct function of the bridge analysis model which, as a separate exercise, was also being used in both the design of the deck girder strengthening and in calculation of the stay cable loads. It also confirmed the care with which the kentledge loads had been weighed and positioned.

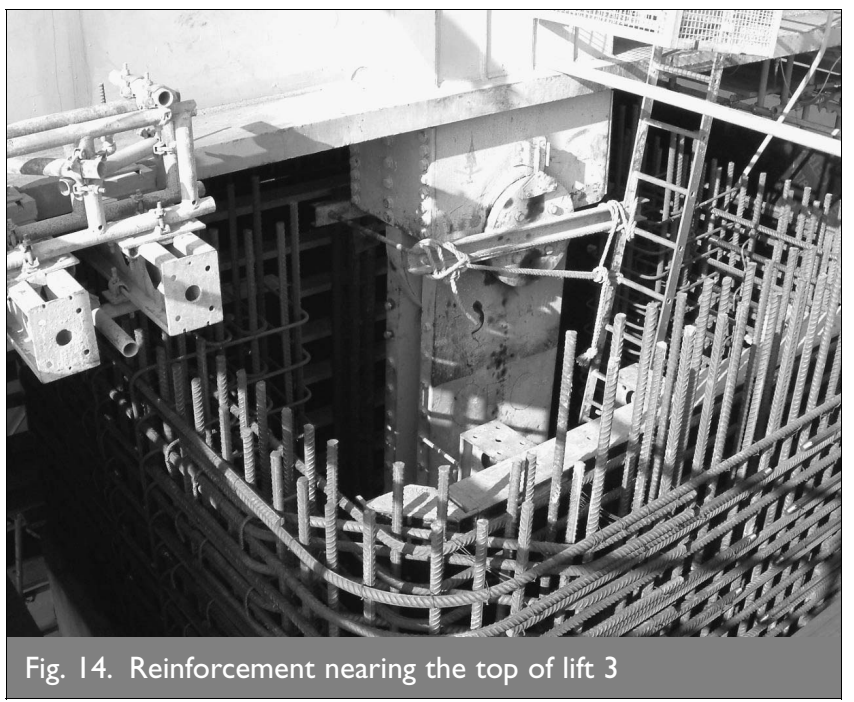




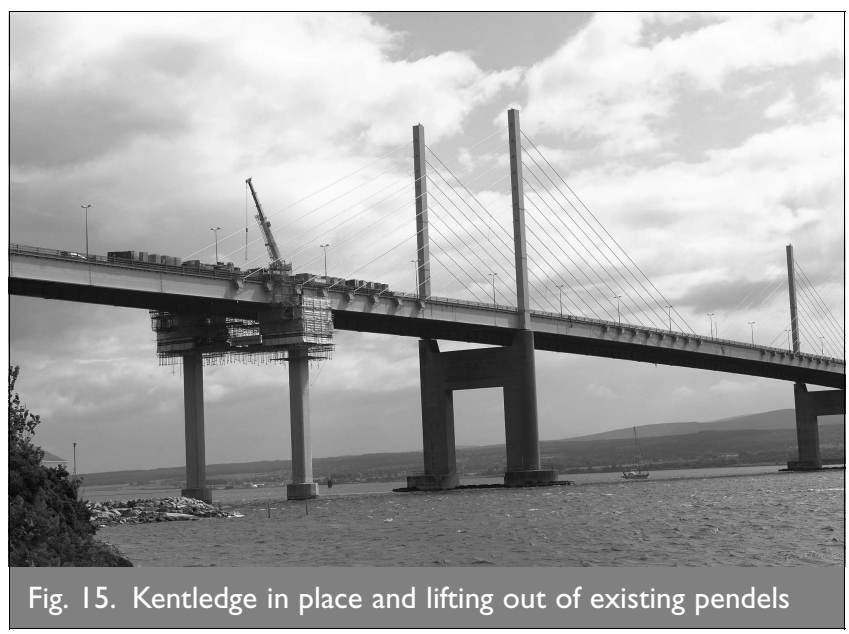

\section{CONCLUSIONS}

The replacement pendels at Kessock rectify the excessive wear problem. Materials and tolerance selection should prolong the service life of the replacement pendels. Nevertheless, the installation of replaceable bushes and the provision of enlarged load-bearing pendel chambers allow for a far easier and less costly maintenance procedure should wear necessitate bush replacement in the future. By repeating the jacking and kentledge method adopted in this project, it is envisaged that the bushes could be replaced within two weekend traffic-management periods (in addition of course to lead-in and lead-out site works periods that may require some ad hoc traffic management to deliver materials, position plant, and so on). Bush replacement now involves only the pendels being rotated out on the pins within the chambers while the other pin is removed; this can be accomplished with equipment from within the chambers.

The replacement of the pendel bearings was completed in June 2003 with minimal disruption to traffic crossing the bridge. The success of the project was due in large part to very careful planning both during design and construction. While the project took six months to design and six months to construct, a very large part of the design and construction planning was focused on the two special weekend periods in which the replacement work was carried out. The course of the project was therefore made all the more interesting given the anticipation with which the overall construction effort developed throughout the construction period towards the crescendo of brief and concentrated periods of activity during which the pendel steelwork was replaced while the chamber walls were subjected to their maximum design loading.

\section{ACKNOWLEDGEMENTS}

The author would like to acknowledge the following for contributing to the success of this project: W. Valentine, R. Johnstone and W. Minto (Bridges Branch, Transport Scotland); J. Murphy (BEAR Scotland Ltd), M. Sime, D. Coultas and M. Murray (Jacobs UK Ltd); principal contractor John Mowlem \&t Company plc and steelwork subcontractor Isleburn Ltd.

\section{REFERENCES}

1. Mcgibвon J. I. and Bоотн G. W. Kessock Bridge: construction. Proceedings of the Institution of Civil Engineers, 1984, 76, No. 1, 51-66.

2. Knox H. S. G., Homberg H. and Deason P. M. Kessock Bridge: design by contractor. Proceedings of the Institution of Civil Engineers, 1984, 76, No. 1, 35-50.

3. Cullen Wallace A. A. and Nissen J. Kessock Bridge: joint engineer's role. Proceedings of the Institution of Civil Engineers, 1984, 76, No. 1, 67-80.

4. Clements L. The Kessock Bridge design-and-build contract, and proposals for managing similar contracts. Proceedings of the Institution of Civil Engineers, 1984, 76, No. 1, 23-34.

5. Clements L., Knox H. S. G., Homberg H., Deason P. M., McGibbon J. I., Booth G. W., Cullen Wallace A. A., Nissen J. and Merrison A. Discussion, design and construction of Kessock Bridge. Proceedings of the Institution of Civil Engineers, 1986, 80, No. 1, 179-214.

6. ERRATA. Kessock Bridge: design by contractor. Proceedings of the Institution of Civil Engineers, 1986, 80, No. 1, 214.

7. British Standards Institution. Steel Castings for General Engineering Use. BSI, Milton Keynes, 1991, BS 3100.

8. Clark L. A. The Provision of Tension and Compression Reinforcement to Resist in-plane Forces. Magazine of Concrete Research, 1976, 28, pp. 3.

9. NieLSEN M. P. Limit Analysis and Concrete Plasticity. CRC Press, Florida, 1999.

10. Institution of Civil Engineers. Conditions of Contract. Institution of Civil Engineers London, Fifth edition, 1986.

\section{What do you think?}

To comment on this paper, please email up to 500 words to the editor at journals@ice.org.uk

Proceedings journals rely entirely on contributions sent in by civil engineers and related professionals, academics and students. Papers should be 2000-5000 words long, with adequate illustrations and references. Please visit www.thomastelford.com/journals for author guidelines and further details. 